\title{
Exploration of the Cultivation of Foreign Language Teaching Innovative Consciousness from the Dialectical Relationship between Language Specification and Innovation
}

\author{
Hong Hong, Cai Jing \\ Nanchang Institute of Science \&Technology,Nanchang 330108,China
}

Keywords: Foreign language teaching, Dialectical relationship, Discourse paradigm, Standardization, Innovation.

\begin{abstract}
In order to the language theoretical research results used by language teaching practice, this paper carries out in-depth analysis for the language nature of different paradigms, so this paper proposes a new cultivation approach of foreign language teaching innovative awareness based on the dialectical relationship between language specification and innovation, and introduces it into the teaching practice. From the change of the language to the discourse paradigm, this paper analyzes the arbitrary and creative language, and to explore the dialectical relationship of the innovative and normative language use. Taking 1000 normative and innovative dialectical relationship sentences as sample, the relationship between the standard and the innovation is studied by using statistical method, and the frequency curve of the innovation has been obtained. Finally, we reflect the lack of foreign language teaching ideas, and discuss the training problems of innovation consciousness in the teaching process.
\end{abstract}

\section{Introduction}

The study of different linguistic paradigms has different language phenomenon, so the conclusion of the language law is also different. Language study on the philosophy and logic as the traditional rules are generally confined to the grasp of words and sentences, and the research on functional language emphasizes on the sentence and discourse [1-3]. In the past, foreign language teaching has attached importance to grammar teaching, but is lack of innovation in the cultivation of students' language use, so it can not meet the growing need for economic and cultural globalization.

The linguistic sign system is founded by Saussure, he pointed out that the linguistic signs have the linear features and the arbitrary nature, therefore, it has caused the controversy of the future generations. Xu Guozhang combined the essence of language teaching and language understanding, and opened up the new path of language theory and teaching practice from the two perspectives of experience and posteriori [4-6]. From the change of the language to the discourse paradigm, the teaching of language has a different revelation through the summary of the different languages essential characteristics. This paper explores the language use of the dialectical relationship between normative and innovative, which has great significance to the cultivation of students' innovative awareness in the process of foreign language teaching.

\section{The Basic Features of Language Standardization and Innovation}

In the exploration of language standardization and innovation, we will naturally consider the basic language characteristics, linguists believe that any animal is essentially different in the language, human language has characteristics of six aspects, including specification, arbitrariness, creativity, and transmission and Macross features [7,8]. The basic process of standardization and innovation is shown in Figure 1. 


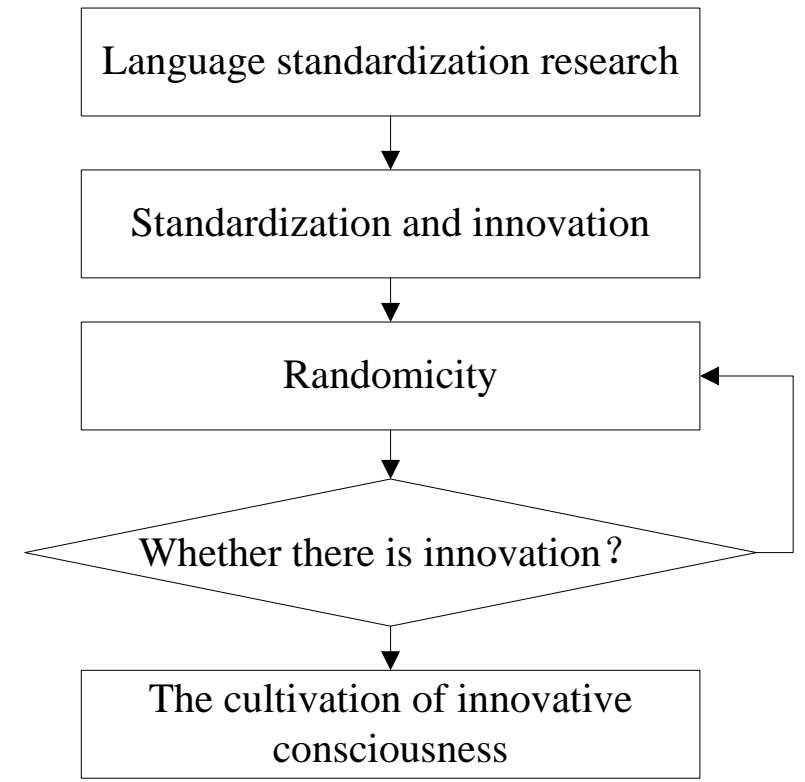

Fig.1 The language specification and innovative research process

Figure 1 shows the study process of language standardization and innovation. In the process of innovation, we need to study the relationship between normative and innovative according to the standard of language, to carry on the arbitrary assumption, and then to judge whether a language is creative, finally to cultivate innovation consciousness.

The Two Traditions of Western Semantic Research. Halliday pointed out that the uniqueness of language cognition was the cognitive results that are not knowledge but meaning [9]. The study of the significance can be divided into two kinds of traditional, one is tend to the tradition of philosophy and logic, it regards language as a rule system; another is folk rhetoric, language is viewed as a kind of resource, two kinds of the research methods on traditional meaning and focus are different.

The essence of language as arbitrary symbol. Language study subjectivists believe that the language research mainly focuses on the object relationship between the symbols, the language symbol is considered as a kind of special social existence, and every language symbols are combined with the specific image and concept $[10,11]$. Of course, language as a symbol has arbitrary, it also has absolute meaning for some specific symbols, such as in French notation, vingt and dix-neuf are on behalf of the above two cases.

The creativity of language as a rule system. Language is unique to humans, the most obvious difference between animals and humans is the creative in language communication, and humans can use a finite set of rules to create an infinite number of sentences ability [12]. The language is creative, it is the focus of language philosophy, but the creativity of language is not limited in the sentence, and is the diversity of language expression significance.

\section{The Dialectical Relationship between Statute and Innovation in the Language Application}

The standardization of language reflects the social attributes of language, it is the individual play in language communication, and it mainly follows the rules of the discourse expression, such as speech appropriateness [13,14]. However, discourse is only innovation, it can justifiably and stunned, and the unity opposites of standardized and innovation is the use of language rules. The unity of standardization and creativity in language must first start from the morpheme, the level of language is conventional, and it is no innovation. Word is composed of morphemes, it is no motivation for monolingual word, and the words of two or more elements are rational. In exceptional circumstances, the language expression needs to create new words to meet the needs of communication [15-17]. For example, in order to show their artistic characteristics, a photographer will create a new word "to-be-seenness" in a photography comment. Through examples show that the normative words is the dominant position, but also has a creative. In the phrase, the normative language is the dominant position, and the innovation is relatively weak. In accordance with the rules, the statement is not only 
normative, but also has a creative, in which sentence group contains a number of small sentence, the specification is relatively weak, and the speaker's subjective consciousness determines the order clause, such as: if it rains tomorrow, we will cancel the trip; we will cancel the trip, if it rains tomorrow.

The expressions of the two sentences are in line with the English habit, but the information structure of the sentence is different, which speaker chooses is based on the context, and they couldn't be a random selection $[18,19]$. In order to study the relationship between the normative and creative language, we chose 1000 sentences as the research sample, and obtain the statistical curves as shown in Figure 2.

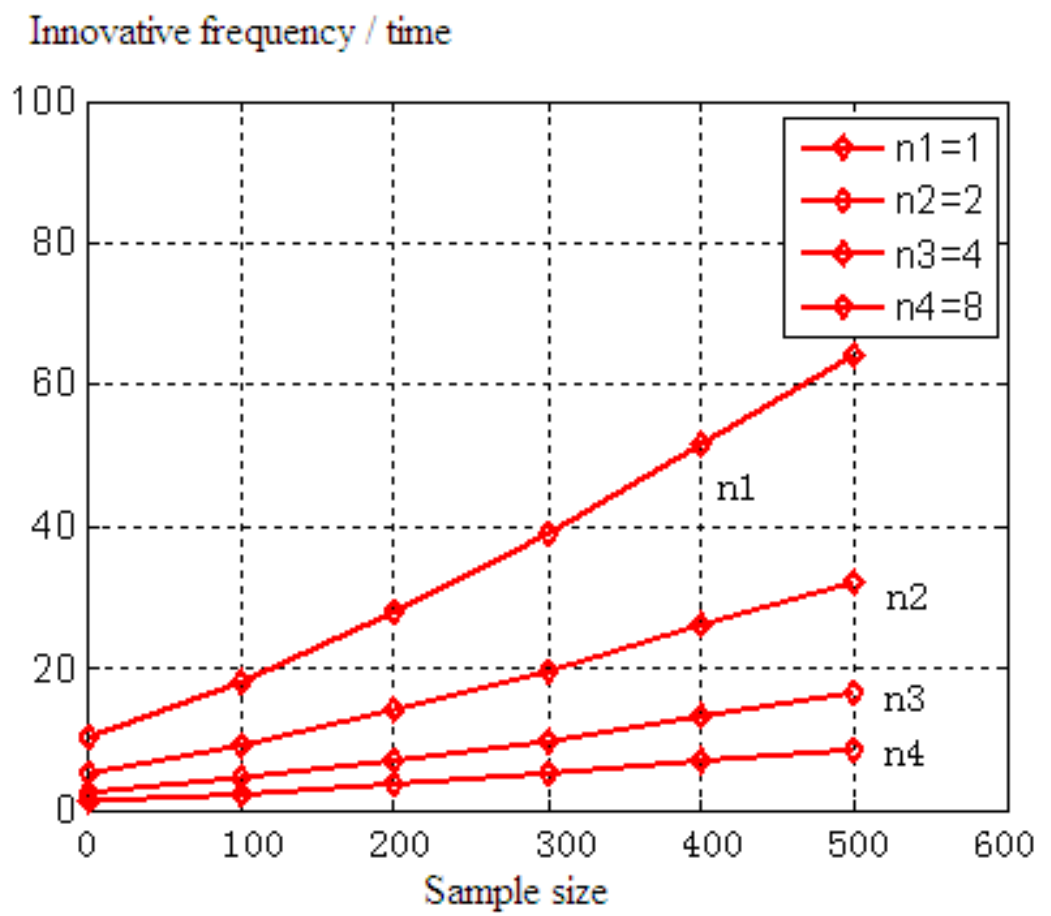

Fig.2 The dialectical relationship statistics between language specification and creative

Figure 2 shows the statistical graph of the dialectical relationship between language normative and creative, in which $n$ shows the proportion of normative. It can be seen from the graph that with the increase of the sample size, the frequency of the innovation is also increased; with the increase of the sentence standard ratio, the innovation has declined.

\section{The Cultivation Problem of Innovative Awareness in Foreign Language Teaching.}

In the past few decades, China has made great achievements in foreign language teaching. However, in the context of economic and cultural globalization, the exchange and fusion between different cultures are expected to better serve the comprehensive opening of foreign language teaching [20]. Foreign language teaching should always maintain the advanced nature of the method, it needs to have a strong sense of responsibility and scientific attitude, to find the problem, analyze the problem and solve the problem, and to reflect and cultivate innovative ideas on the traditional teaching,

Foreign language education idea innovation. In the foreign language teaching, we tend to the basic characteristics of one-sided understanding language, and has brought the practice of misunderstanding. If understanding language characteristics and emphasizing the language standard, the language use of innovation are not in place, the concept of the past language teaching can not be ignored.

The cultivation of innovative awareness in foreign language teaching. The linguistic normative change has a more profound understanding for the dialectical relationship between language standardization and innovation. The system's functional language can be as a reference observation 
method, so that the discourse is is highly appreciated to seek innovation in building a discourse. How to cultivate learners' innovation ability, it can be language learning paradigm as a focal point.

\section{Summary}

According to the functional language system and discourse, it is found that the language standardization and unification have the relationship of the unity of opposites, and the level of language is higher, the innovation is stronger. The transformation of the language form has new ideas for the nature of language. In language teaching, we can cultivate the students' innovative consciousness with the dialectical relationship between the standard and the innovation. Since entering this century, education has attached great importance to the cultivation of the prsonnel quality and ability, and wether foreign language ability has the innovation consciousness and cultivate innovation ability, it will cause the education policy makers and the industry wide attention, which has far-reaching influence for foreign language teaching research.

\section{References}

[1] F.Y. Li. The application of multimedia and its thinking in English teaching. China's information technology education, 2014(8): 43-44.

[2] L.J. Song. Analysis of students' psychological characteristics in English teaching of middle school and learning, 2014(3): 55-56.

[3] X.L. Quan. The reconstruction translation framework as the translation purpose - Lin Shu's novel translation from the perspective of Mona Baker's narrative theory, Journal Huaibei normal university, 2012 (2): 117-121.

[4] L. Shao. L. Shao. the narrative interpretation of Translation and Syria in life and death. Shandong foreign language teaching, 2014(6): 96-101.

[5] L. Shao. The narrative world in the translation- an analysis of Mo Yan's "life and death". Foreign language teaching and research, 2013 (2): 68-71.

[6] L. Shao. Narrative stylistic trend in western translation theory. Foreign language studies, 2014(4): 86-92.

[7] M.Y. He. The relationship identification between conceptual metaphor and politics. Foreign language, 2013(3): 48-52.

[8] S. Li. The construction and reconstruction of the framework in political speech as the case study of the cultural signs, metaphor and negation. Journal of Hainan University, 2014(5): 112-115.

[9] Y. He, W.Q. Wang, F. Xue. Research on massive data mining based on cloud computing. Computer technology and development, 2013, 23(2): 69-72.

[10] Q.P. Yang, Y. Ding, Y.M. Qian. Research on data mining platform and its key technology based on cloud computing. ZTE technology, 2013,19(1): 53-60.

[11] K. Li, Z. Chang. Design and implementation of the parallel data mining system based on cloud computing. Microcomputer information, 2014, 27(6): 121-123.

[12] G.L. Sun, H.L. Qi. The spam filtering of logic regression based on online ordering. Journal of Tsinghua University, 2013, 53(5): 734-740.

[13] B.T. Liu. Research on data mining algorithm based on rough set. China West technology, 2014, 10(14): 11-12.

[14] J. Song. English teaching should pay attention to the students' emotion. Chapter, 2013(5): 92-93. 
[15] Y.M. Zhu. A new thinking on improving students' learning interest and motivation in English teaching. China's off campus education, 2014(4): 105-106.

[16] Y. Yang. The advantages and disadvantages of multimedia teaching in English teaching and learning. Journal of Jilin radio and Television University, 2013(6): 146-147.

[17] L. Fu. The use of hierarchical teaching in English teaching. Hope monthly, 2014(8):100-101.

[18] X.Q. Yu. The formation and breakthrough of Matthew effect in basic education. Teaching and management, 2014 (9): 60-61.

[19] Y.H. Zhang. A study on the dynamic evaluation model of web writing teaching in college English. Foreign language circles, 2014(4): 73-81.

[20] D.H. Mao. Research on the implementation of higher vocational mathematic hierarchical teaching. Journal of Chongqing vocational and technical college, 2014, 16(4): 43- 44. 